\title{
Protracted Cardiac Neurosis with Congenital Heart Disease in One of Identical Twins
}

\author{
L. G. SCARTH AND D. W. K. KAY \\ From the Department of Psychological Medicine, Royal Victoria Infirmary, Queen Victoria Road, \\ Newcastle upon Tyne, NE1, 4LP
}

There is growing appreciation of the ease with which iatrogenic neuroses may be induced in patients complaining of heart symptoms, whether or not organic disease is present. Nevertheless, this aspect of the management of heart disease receives little attention in textbooks of medicine or cardiology, where "The Psychoneuroses" are usually dealt with separately in a chapter which has little connexion with anything else.

The following is a case report of a patient who presented for psychiatric treatment in adult life for a neurosis which dated from the disclosure of ventricular septal defect at the age of 11 . Her twin, presumed identical monozygotic, has no heart lesion, and may be regarded as a control. She is psychiatrically healthy.

\section{Case Report}

The twins, Ann (the patient) and Jane were born in 1930 after a difficult labour. The father has suffered from asthma, but the mother and a younger sib are healthy. Both twins thrived, developmental milestones were normal, and neither showed any conspicuous neurotic traits. Ann was more self-conscious, prim, and tidy, Jane more prone to tempers; Jane was also a little taller and fatter. Ann sustained an uncomplicated skull fracture at the age of 9, and later in childhood contracted jaundice and "rheumatic" arthritis, illnesses that Jane missed. Recovery, however, was uneventful. The twins were average at school work, but both were artistic, drawing and singing well, and learned to play the piano. They both swam, danced, and skated. Ann is said to have been the leader, but Jane the more persistent.

Cardiac History. When Ann was aged 11, the school medical officer informed the mother that she had a heart murmur. She spent a day at a teaching hospital where numerous tests were done, photos taken, and she was shown to students. The mother says that she was told to keep her in bed. Later she returned to school, but was not permitted to attend in bad weather or to play games. After leaving school she improved and found work as a piano tuner but lost time because of what were presumed to be extrasystoles ("bumps"), which caused intense anxiety.

When she was aged 27 cardiac catheterization was carried out and a ventricular septal defect (VSD) with a small shunt was demonstrated. Six years later, in view of her intractable symptoms, an open operation was performed and a defect $1.5 \mathrm{~cm}$. in diameter closed. Her symptoms, however, were not improved in any way.

Psychiatric History. After the investigations when Ann was 11, the mother got the impression, rightly or wrongly, that the prognosis was regarded as ominous. She was shocked, and convinced that Ann would not survive to adult life. Ann's reaction was immediate; she could not sleep, felt "bumps" in the chest, and was often panic-stricken for fear she would die. She behaved like an invalid, becoming irritable and demanding, while the mother remained anxious, protective, and solicitous. Jane was not obviously distressed, continued with her activities, and did well at school. Six months after Jane married, Ann also married but has had no children.

A year after her marriage she developed "blackouts" which brought about several admissions to hospital. She also took an overdose of sleeping tablets. At the age of 23 she first came under psychiatric care; the letter of referral stated "she has become very frightened when she feels her heart jump and thinks it may stop. As a consequence of this, she has had screaming attacks, locked herself in various rooms when the doors have to be broken in to get her out and she has repeatedly threatened suicide..." She was found to be suffering from severe attacks of anxiety associated with her "bumps", and a conviction that these would cause her sudden death. She proved resistant to treatment, and later took another overdose. She was admitted to a psychiatric unit on several occasions without lasting results. Within weeks of the heart operation the "bumps" recurred, together with blackouts and an intensification of her fears. She collapsed at home and in the street and was several times rushed to hospital, 
without, however, any physical abnormality being discovered.

Present Psychiatric State. At the age of 37, Ann is an extremely tense and rather depressed woman, wholly preoccupied with her heart action. She tends to be histrionic; for example she often wears a low-cut dress revealing a livid scar, and covers her face with white powder with a death-like effect. At home she is entirely dependent on her husband and mother, and cannot go out alone.

Physical Condition. Before and after the heart operation she was seen by cardiologists on several occasions. Apart from a very strong thrill and an exceptionally loud systolic murmur, which almost disappeared after the operation, the findings were always negative. Electrocardiograms throughout the illness showed no abnormality.

Attention had earlier been given to the possibility that some of her symptoms were due to attacks of paroxysmal tachycardia, and treatment with quinidine was instituted, but without effect. Moreover, during her several spells in hospital, including over 5 months in the Psychiatric Unit, attacks of paroxysmal tachycardia, though watched for, were never observed despite the persistence of symptoms. Even single extrasystoles were never actually observed clinically or seen on the cardiogram. The final opinion about her physical state by the cardiologist (Dr. W. G. A. Swan) who saw her most recently (1967) was that "she remains (sic) entirely a psychiatric problem".

Jane is a mature woman, with one child. She is even tempered and independent and without psychiatric abnormality. Her only psychiatric disturbance occurred during her pregnancy when she became convinced that she was developing eclampsia and would die. She received no special treatment, recovered after childbirth, and has remained well.

Zygosity Tests. The twins are 1dentical in the details of their appearance and neither are "tasters" of phenylthiocarbamide. Dermatoglyphic and blood group studies, combined with the transferrin, acid phosphatase, phosphoglucomutase, and adenylate kinase patterns (all identical) give an absolute probability of monozygosity of 0.99576 .

\section{Discussion}

Nora et al. (1967), reviewing previously reported cases, found that of 15 recorded twin pairs in whom ventricular septal defect was present, only one pair (monozygotic) was concordant, while 7 monozygotic and 7 dizygotic pairs were discordant. Thus ventricular septal defect appears to be, largely, environmentally determined in utero, and the fact that our twin pair is discordant for ventricular septal defect cannot itself be regarded as evidence that they are not monozygotic.
As regards neurosis, Slater and Shields (1969) concluded that though monozygotic twin pairs are discordant for anxiety neurosis in about 50 per cent of cases, the form of neurosis, when present in both, is strikingly similar, much more so than in the case of dizygotic twins. On the other hand, the occurrence of neurotic illness and its severity may be determined largely by environmental or acquired factors. This distinction appears to be true of our twin pair, whose illnesses were similar in form but altogether unlike in severity and duration. Naturally, where neurosis is concerned, "concordance" and "discordance" are relative terms.

The unlikely possibility that the neurosis and the heart lesion had a common origin is belied by the patient's normal development until the age of 11 when she became the focus of medical concern. One could suppose that the earlier illnesses might have rendered the mother more sensitive about this twin's health, though there is nothing to suggest that this was so. As regards the patient's head injury 2 years earlier, recovery was uneventful, without any complications referrable to the injury, the "blackouts" which she experienced as an adult were not clinically epileptic in form, and the electroencephalogram was then normal. On the other hand, the immediate and dramatic reaction to the disclosure of the lesion is prima facie evidence of its causal role in the protracted neurosis. Nevertheless, it might be argued that this event and the investigations that followed merely released neurotic tendencies which were already present and which would in any case sooner or later have become manifest. Here lies the significance of the "experiment of nature" which provided the identical twin as a control. Apart from the one short episode, the twin has remained healthy; and one may conclude, with retrospective wisdom, that if the emotionally traumatizing and invaliding consequences of the discovery of the heart abnormality could have been avoided, the subsequent history would indeed have been different.

The histories of the twins appear to confirm in a striking and unusual manner the importance placed by Apley, Barbour, and Westmacott (1967), among others, on the need for the most careful assessment of both the child and the family in the management of cardiac lesions.

\section{Summary}

A pair of monozygotic twins discordant for ventricular septal defect and for neurosis is described. The protracted psychological invalidism of the patient began with the disclosure of the heart lesion at the age of 11 years. The presence of the normal 
identical twin suggests that, but for this, she would have remained healthy, and indicates the extreme importance of the psychological aspects of the management of cardiac lesions in children.

We are indebted to Dr. Robert Orton for his permission to publish Ann's case history and for his pertinent comments; to Mr. A. E. Mourant of the M.R.C. Blood Group Reference Laboratory for the blood group studies; to Dr. E. Robson of the M.R.C. Human Biochemical Genetics Research Unit for the enzyme studies; and to Dr. D. F. Roberts, Reader in Human
Genetics, University of Newcastle upon Tyne, for calculation of the zygosity probabilities.

\section{References}

Apley, J., Barbour, R. F., and Westmacott, I. (1967). Impact of congenital heart disease on the family: preliminary report. Brit. med. F., 1, 103.

Nora, J. J., Gilliland, J. C., Sommerville, R. J., and McNamara, D. G. (1967). Congenital heart disease in twins. New Engl. F. Med., 277, 568.

Slater, E., and Shields, J. (1969). Genetical aspects of anxiety. In Studies of Anxiety, pp. 62-71. Ed. by M.H.Lader. Royal Medico-Psychological Association, London. 